\title{
CMA "effectively abandoning" role as national voice on physician issues, says Ontario Medical Association
}

— Cite as: CMAJ 2018 August 27;190:E1028-9. doi: 10.1503/cmaj.109-5652

Posted on cmajnews.com on Aug. 10, 2018.

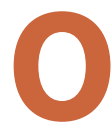

ntario doctors are pushing back against a shift in direction at the Canadian Medical Association (CMA), including proposed changes that may shrink the influence of provincial medical associations on the national organization's priorities.

In a letter to members, the Ontario Medical Association (OMA) raised concerns that the CMA is "effectively abandoning" its role as a federal advocate for physicians. The OMA also announced it will no longer enrol members automatically for joint CMA membership. (According to CMA data, there are 30175 doctors in Ontario $36 \%$ of Canada's physician workforce.)

"A lot of physicians are worried that, as the CMA expands its focus to the health care system, they're walking away from focusing on physician issues," said OMA president Dr. Nadia Alam. "There are issues that we all face as a national voice and that voice is no longer being heard at the CMA."

Last year, the CMA adopted a threeyear plan to become a broader "social enterprise" for improving the health of Canadians. As part of this plan, the CMA recently sold its financial services company, MD Financial Management, to Scotiabank for almost $\$ 2.6$ billion.

The CMA also proposed bylaw changes to streamline its board and eliminate general council, an annual meeting at which provincial delegates debate motions to direct the association's policies. These bylaw changes will be subject to a vote later this month at a final general council, which has been cut from several days to two hours.

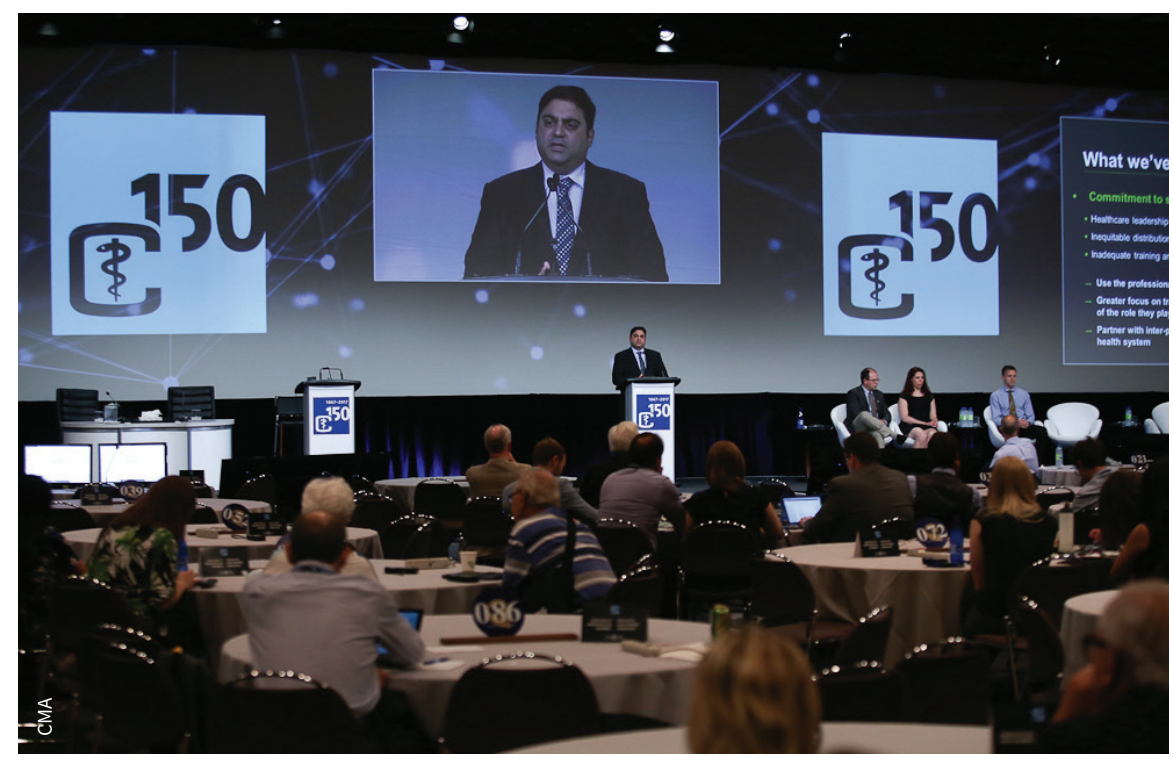

The Ontario Medical Association has raised concerns about changes at the Canadian Medical Association, such as the elimination of the CMA's annual general council meeting.

The lack of consultation about these changes suggests a concerning shift in CMA's relationship to its members and provincial medical associations, said Alam. "As an observer, it looks like the CMA is consolidating power to the board without engaging members first."

Many doctors felt betrayed by the sale of MD, said Alam. "The CMA was facing financial uncertainty, so as an organization, the sale probably made sense for them, but the unintended consequence has been it has not made sense for the members and there may be fallout from that." On social media, some members threatened to leave both MD and CMA. Among the provincial medical associations, "there's a feeling of being left behind."

CMA is proposing to reduce its board to a representative from each jurisdic- tion, plus a nationally elected president. Previously, Ontario had five representatives on the 20-plus member board, in proportion to the province's larger physician workforce. "While it may be appropriate to streamline the board, there's no indication whether this is the best way to do it," said Alam. "It feels very unilateral."

The national association is also proposing to replace general council with an annual health summit that will be open to a wider range of participants, and to create a process for members to submit policy proposals throughout the year.

"If there were more details provided and a properly thought out transition plan, we could be supportive, but what we're asking the CMA to do is defer these 
bylaw changes for a year and do consultation properly," said Alam.

Considering these concerns, it no longer makes sense for OMA to collect CMA dues from its members, said Alam. This may hurt CMA's membership numbers, as Ontario physicians will have to seek out and pay separately for membership that was previously automatic.

"If the relationship is changing, we need to give our members a chance to step back and decide whether they want the CMA to be their voice," said Alam.

The CMA said its core mandate of supporting physicians hasn't changed, just expanded in scope. "We intend to bring a strong physician voice to the table and bring meaningful change - for the profession and for the public," the CMA said in an email response to questions from CMAJ.

According to the CMA, the proposed bylaw changes are intended to make the national association more inclusive of all its members, as well as to build bridges beyond the medical profession. The CMA also stated that it has engaged with members, the provincial medical associations and affiliates to discuss these changes over the past two years. "The CMA has always been and will always be a membercentred association."

Lauren Vogel, CMAJ 